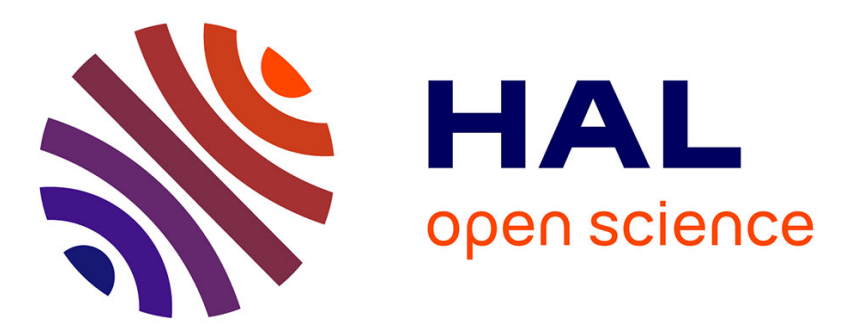

\title{
Liquid crystal ionic self-assembly and anion-selective photoluminescence in discotic azatriphenylenes
}

Jia Dai, Ke-Qing Zhao, Bi-Qin Wang, Ping Hu, Benoît Heinrich, Bertrand

Donnio

\section{- To cite this version:}

Jia Dai, Ke-Qing Zhao, Bi-Qin Wang, Ping Hu, Benoît Heinrich, et al.. Liquid crystal ionic selfassembly and anion-selective photoluminescence in discotic azatriphenylenes. Journal of Materials Chemistry C, 2020, 8 (12), pp.4215-4225. 10.1039/c9tc05829j . hal-03007434

\section{HAL Id: hal-03007434 https://hal.science/hal-03007434}

Submitted on 17 Nov 2020

HAL is a multi-disciplinary open access archive for the deposit and dissemination of scientific research documents, whether they are published or not. The documents may come from teaching and research institutions in France or abroad, or from public or private research centers.
L'archive ouverte pluridisciplinaire HAL, est destinée au dépôt et à la diffusion de documents scientifiques de niveau recherche, publiés ou non, émanant des établissements d'enseignement et de recherche français ou étrangers, des laboratoires publics ou privés. 


\title{
Liquid crystal ionic self-assembly and anion-selective photoluminescence in discotic azatriphenylenes $\uparrow$
}

\author{
Jia Dai, ${ }^{a}$ Ke-Qing Zhao, ${ }^{\text {*a }}$ Bi-Qin Wang, ${ }^{a}$ Ping Hu, ${ }^{a}$ Benot Heinrich ${ }^{\text {b }}$ and \\ Bertrand Donnio *b
}

We report on the straightforward synthesis of a new series of ionic discotic liquid crystals based on positively charged azatriphenylene. In our design, the quaternized azatriphenylene core is surrounded by four to six flexible aliphatic chains and various types of anions, including small inorganic anions (i.e. $\mathrm{Br}$,

I, $\mathrm{NO}_{3}, \mathrm{BF}_{4}, \mathrm{PF}_{6}$ ), and organic ones such as triflate, bis(trifluoromethylsulfonyl)imide, tosylate, saccharinate, $\mathrm{D}$ and $\mathrm{L}$ camphorsulfate, alkylsulfonates, and alkylsulfates. The mesophases and thermal behaviour of the salts were characterized by polarizing optical microscopy, diff erential scanning calorimetry, thermal gravimetry and small-angle X-ray scattering. A classical hexagonal columnar mesophase, i.e. p6mm- Col $_{\text {hex }}$, was observed for most salts. Two exotic new phases were however identified for four compounds, namely a mesophase with a hexagonal lattice of $\mathrm{p} 3 \mathrm{~m} 1$ symmetry (Hex), and another mesophase with a rectangular lattice of pseudo-hexagonal geometry (i.e. $\mathrm{a} / \mathrm{b}=\mathrm{O} 3)$ of $\mathrm{p} 2 \mathrm{mg}$ symmetry $\left(\mathrm{Rec}_{\mathrm{phex}}\right)$. The former results from the bulkiness of the triflimide anion and the arrangement of columns into a honeycomb lattice, whereas the latter is induced by the clustering of three columns, disposed according to a low-symmetry rectangular lattice. Their temperature ranges and stabilities strongly depend as expected on the anion type and the number (and length) of the alkyl side-chains (O- and $\mathrm{N}$-alkyl, respectively), highlighting the delicate balance and interplay between van der Waals, electrostatic and $\mathrm{p}-\mathrm{p}$ core interactions. The UV/Vis absorption and fluorescent emission spectra were measured, and a strong yellow light photoluminescence was observed depending on the anion type, whereas anion-selective luminescence was observed in thin films. The neutral azatriphenylene precursor, 6,7,10,11-tetrakis(hexyloxy)dibenzo[f,h]isoquinoline, is also an interesting luminophore, showing an absolute emission quantum yield of $75 \%$, while the corresponding salts exhibit anion-selective emission quantum yields as high as $20 \%$.

\section{Introduction}

Ionic liquids are ionic compounds with melting points below $1001 \mathrm{C}$, and, as synthesized low- or non-volatile liquids and electrolytes, have found numerous industrial applications as green solvents for chemical reactions, crystallizations and extractions, and as electrolytes for batteries and energy storage devices. ${ }^{1,2}$

Of timely interest, ionic liquids have also recently been studied as $\mathrm{CO}_{2}$ capture materials, ${ }^{3}$ environmentally friendly explosives and propellant fuels. ${ }^{4}$ Liquid crystals, as unique ordered and

\footnotetext{
${ }^{a}$ College of Chemistry and Material Science, Sichuan Normal University, Chengdu 610066, China. E-mail: kqzhao@sicnu.edu.cn

${ }^{\mathrm{b}}$ Institut de Physique et Chimie des Matériaux de Strasbourg (IPCMS), CNRS-Université de Strasbourg (UMR 7504), 67034 Strasbourg, France. E-mail: bertrand.donnio@ipcms.unistra.fr $\dagger$ Electronic supplementary information (ESI) available: Experimental techni- ques, synthesis, POM, TGA, DSC, ${ }^{1} \mathrm{H}$ and ${ }^{13} \mathrm{C}$ NMR, HRMS, SAXS, DFT.
}

nanostructured fluids, represent another important class of soft materials. Their dynamic nature, function-integration and stimuliresponsiveness have been successfully utilized on ubiquitous information displaying devices for about half a century. For the last two decades or so, liquid crystals have also been extensively studied as mesophase semiconductors. ${ }^{5-15}$ Therefore, the synergistic hybridiza- tion of ionic liquids and liquid crystals promises new and interesting

industrial and materials opportunities.

Ionic liquid crystals (iLCs) ${ }^{16-23}$ are attracting much attention and are genuinely emerging as multifunctional self-assembled materials due to their natural tendency to self-organize into long-range anisotropic nanostructures with well-defined segre- gated ionic and electronic conducting channels, that may be used as electrolytes in Li-ion batteries, fuel cells, as well as dye-sensitized solar cells. As dynamic ordered materials, iLCs possess the best properties of both ionic liquids and liquid crystals, combining electrostatic and $\mathrm{p}-\mathrm{p}$ core interactions, with the nanosegregation between alkyl chains, ionic moieties 
and aromatic cores. ${ }^{17}$ iLCs therefore possess tremendous potential applications such as ordered reaction media, ${ }^{16}$ anisotropic ionic ${ }^{24-26}$ and electronic ${ }^{27,28}$ conductions, and transport media, ${ }^{29}$ media for alignment of single wall carbon nanotubes (triphenylene-based ionic discogens show $\mathrm{Col}_{\text {hex }}$ and bicontinuous cubic mesophases), ${ }^{27,30,31}$ applied in biological field as siRNA transfection vectors. ${ }^{29}$ Essentially most iLCs so far reported, possess one or two alkyl tails connected to either a small ionic moiety or a rod-like core, and for most of them, show smectic phases, ${ }^{17,32-37}$ with only a few cases displaying columnar phases. ${ }^{38,39}$ In contrast, studies of ionic discotic liquid crystals (iDLCs) with a discotic core and displaying columnar mesophases, ${ }^{40-42}$ are however only just emerging, and only few examples have been reported so far. DLCs with polycyclic

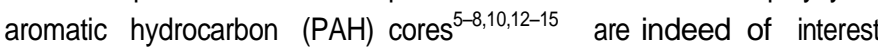
since they spontaneously self-organize into columnar mesophases, and possess one-dimensional electronic charge hopping pathway along the molecular columns with fast charge carrier drift mobility. DLC semiconductors are studied as active materials in organic thin film devices, such as photovoltaic solar cells, organic lightemitting diodes, and field-effect transistors. Up to now, the design of iDLCs consists mainly in the peripheral decoration of the neutral triphenylene discotic core by pending pyridinium, ammonium, guanidinium or the emblematic imidazolium units, connected to the discotic unit through soft alkyl spacers. ${ }^{18,19,43-53}$ They usually show columnar mesophases near room temperature and over large temperature ranges. Inversely, imidazolium or other suitable cations may be used as connectors between triphenylene units to yield dimeric systems. ${ }^{48,50}$ Other systems include bis-triphenylene derivatives connected through crown ethers whose mesophases' stabilities are enhanced upon the host-guest complexation to various cations. ${ }^{54}$ lonic tapered ${ }^{55-57}$ and dendronized ${ }^{58}$ molecular systems have also been reported with various types of counterions and found to self-organize into columnar (and cubic) mesophases. Overall, few examples of conjugated core-charged iDLCs with heterocyclic cores containing oxygen, nitrogen or sulfur atoms have been reported. ${ }^{40-42}$

The synthesis of novel iDLCs is still facing big challenges, as the construction of charged heterocyclic aromatic hydrocar-bons is rendered more difficult by more complex synthetic methodologies based on coupling reactions of variable efficien- cies, and their extremely tedious purifications. ${ }^{42}$ Here, we report a simple molecular design and straightforward synthesis of the azatriphenylene molecular unit, i.e. $\mathrm{N}$-heterocyclic aro- matic, 2, and of the corresponding series of quaternized salts 3 and 4 (Scheme 1) with anions such as $\mathrm{Br}, \mathrm{I}, \mathrm{NO}_{3}, \mathrm{BF}_{4}, \mathrm{PF}_{6}$, triflate $\left(\mathrm{CF}_{3} \mathrm{SO}_{3}-\mathrm{TfO}\right)$, bis(trifluoromethylsulfonyl)- imide $\left(\mathrm{Tf}_{2} \mathrm{~N}\right)$, tosylate (TsO), saccharinate (sac), D and L camphorsulfate (CS ), alkylsulfonates $\left(\mathrm{C}_{\mathrm{n}} \mathrm{H}_{2 \mathrm{n}+1} \mathrm{SO}_{3}\right)$, and alkyl- sulfates $\left(\mathrm{C}_{\mathrm{n}} \mathrm{H}_{2 \mathrm{n}+1} \mathrm{SO}_{4}\right)$. Their physical properties can be tuned by the alkyl chain length on the N-substituent (methyl and hexyl) and the overall number of aliphatic chains, as well as by the size and nature of the anion. Overall, the organic salts 3 and

4 exhibit high thermal stability, strong photoluminescence in solution and solid films, and stable columnar mesophases compared to their neutral hexa(alkoxy)triphenylenes analogues.

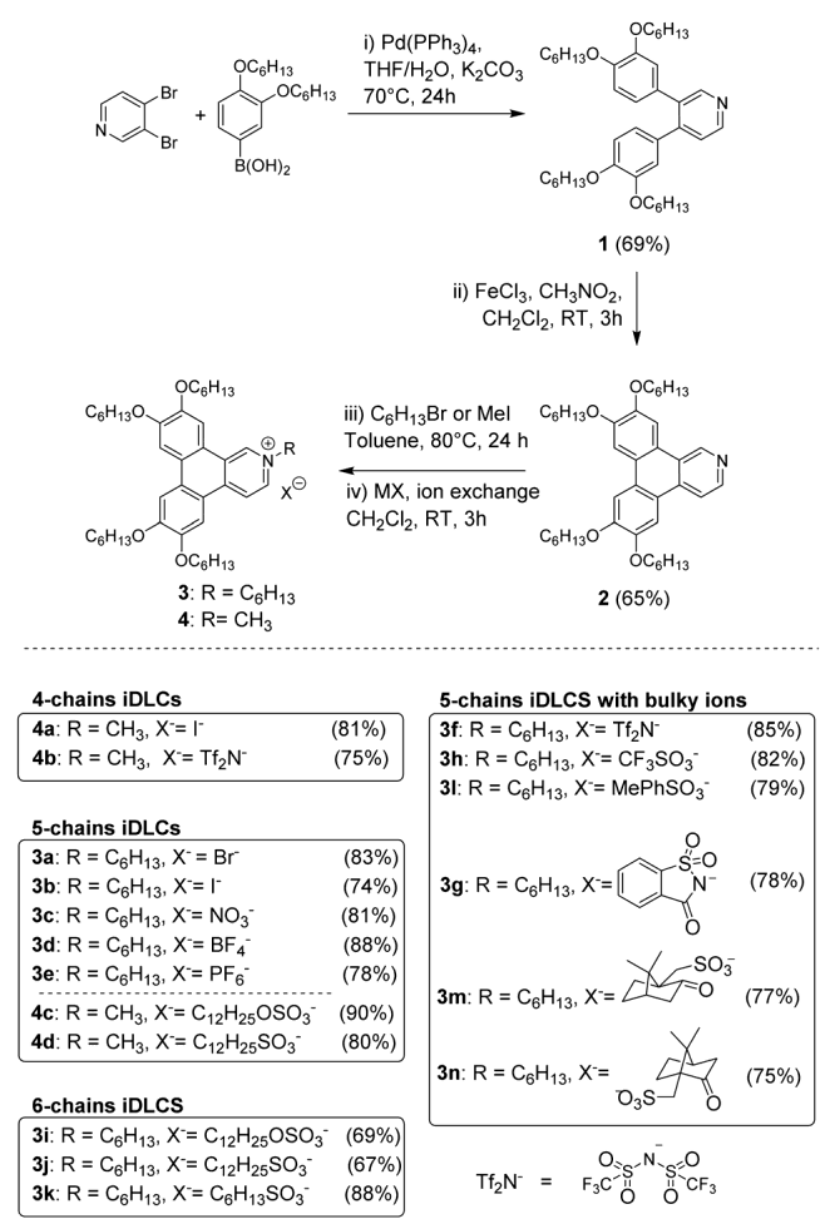

Scheme 1 Synthetic conditions, nomenclature and yields of azatriphenylene 2 and corresponding quaternized ionic discotic liquid crystal salts 3 and 4 .

\section{Results and discussion}

Molecular design, synthetic methodology

Designing and synthesizing iDLCs possessing charged aromatic cores is slightly more challenging than replacing the side chains of a discotic LC by lipophilic fragments bearing ionic ammonium, pyridinium or imidazolium end groups. ${ }^{19,20}$ By analogy to triphenylene DLC, the archetype molecular structure for columnar mesogens, ${ }^{5}$ we considered a structurally related discogen with a positively charged core by replacement of one of the $\mathrm{C}$-atom by a $\mathrm{N}$-atom. Such an azatriphenylene derivative, bearing four diverging alkoxy chains, i.e. 6,7,10,11 tetrakis(hexyloxy)dibenzo[f,h]isoquinoline, can be readily obtained in two successive coupling reactions, followed by the subsequent $\mathrm{N}$-alkylation to connect a fifth side-chain to promote the formation of columnar mesophases.

Within this molecular design, three structural parameters can thus be independently and simply varied, including the length of the chains (O- and/or $\mathrm{N}$-alkyl chains), the type and size of the anion, to allow the tuning of the columnar mesophases symmetry, thermal stability, solubility, as well as the photo- physical properties (Scheme 1) 
Keeping the above design in mind, we tested two diff erent synthetic routes for preparing the azatriphenylene derivative 2 (Scheme 1). According to our previously reported method ${ }^{59}$ for the synthesis of unsymmetrical substituted triphenylenes, we first prepared o-phenylpyridinebenzene (i.e. 4-( $3^{0}, 4,4^{0}, 5$-tetrakis- (hexyloxy)$\left[1,1^{0}\right.$-biphenyl]-2-yl)pyridine) by Suzuki-Miyaura cross- coupling reaction between 2-bromobiphenyl derivative and pyridinyl-4boronic acid. However, the following $\mathrm{FeCl}_{3}$-catalysed oxidative intramolecular aryl-aryl coupling did not give the desired azatriphenylene 2, possibly due to lower p-electron density of the pyridine core. $^{60}$ For an alternative synthetic route (Scheme 1), 3,4dibromopyridine was first reacted with the readily accessible 3,4di(hexyloxy)phenylboronic acid by Suzuki cross-coupling reaction (Scheme $\mathrm{S} 1, \mathrm{ESI} \dagger$ ), followed by the $\mathrm{FeCl}_{3}$-catalysed oxidative aryl-aryl intramolecular coupling. ${ }^{59}$

This two-steps method gave the desired azatriphenylene 2 in an overall yield of $65 \%$. N-Alkylation of 2 with 1 -bromohexane or iodomethane in hot toluene produced after $24 \mathrm{~h}$ the corresponding ionic discogen $3 \mathrm{a}$ and $4 \mathrm{a}$, respectively, in yields greater than $80 \%$.

The 16 ionic azatriphenylene-based salts $3 b-n$ and $4 b-d$ were obtained by anion exchange metathesis reaction of various inorganic or organic salts in dichloromethane with both precursory salts, $3 \mathrm{a}$ and $4 \mathrm{a}$, respectively, and obtained in satisfactory yields (synthetic details are given in ESI $\dagger$ ). All synthesized salts were characterized by ${ }^{1} \mathrm{H}$ and ${ }^{13} \mathrm{C}$ NMR spectroscopy and elemental analysis (Table S8 and Fig. S8-S28 in ESI†). For all compounds of the series 3, elemental analyses are satisfactory (with a deviation from theoretical carbon \% content smaller than $0.4 \%$ for most, and just below $0.5 \%$ for $3 \mathrm{c}$ and 31 , ESl $\dagger$ ). For compounds $4 \mathrm{a}$ and $4 \mathrm{~d}$ of series 4 however, this deviation is slightly more substantial, by ca. $0.9-1 \%$, which may be associated to some weight-loss occurring at an early stage, i.e. below $1001 \mathrm{C}$ for $4 \mathrm{~d}$ (loss of a water molecule) and below $1501 \mathrm{C}$ for $4 \mathrm{a}$ (partial demethylation, Fig. S2, ESI $†$ ). These analyses supported the targeted molecular structures.

\section{${ }^{1} \mathrm{H}$ NMR characterization}

The structure and nature of the anions impact strongly the chemical and physical properties of the entire ionic liquids, and consequently those of the iLCs as well. ${ }^{1} \mathrm{H}$ NMR is known as an efficient spectroscopic technique to explore these various interactions between anions and cations, and particularly the hydrogen bond accepting ability, which is extremely relevant for some ionic liquids such as imidazoliums. ${ }^{61}$ For the ionized azatriphenylene compounds 3 and 4 , the chemical shift values of ${ }^{1} \mathrm{H}$ NMR on the aromatic core protons, essentially the displacements of the signals corresponding to both neighboured protons of the $\mathrm{N}$ atom of the pyridine fragment, are obviously aff ected by the quaternization and display strong relationships with the nature of the anion. For instance, $\mathrm{Br}$ and $\mathrm{I}$ have strong $\mathrm{H}$-bonding forming ability with such types of protons, and consequently, their chemical shift values in compounds $3 \mathrm{a}$ and $3 \mathrm{~b}$ (Table S8 and Fig. S1, ESI $\dagger$ ) are large, and substantially deshielded with respect to those of 2 (Fig. 1a). In contrast, for fluorine-containing anions such as $\mathrm{BF}_{4}, \mathrm{PF}_{6}$ and $\mathrm{Tf}_{2} \mathrm{~N}$ (except for the TfO compound whose proton shift seems unaff ected),
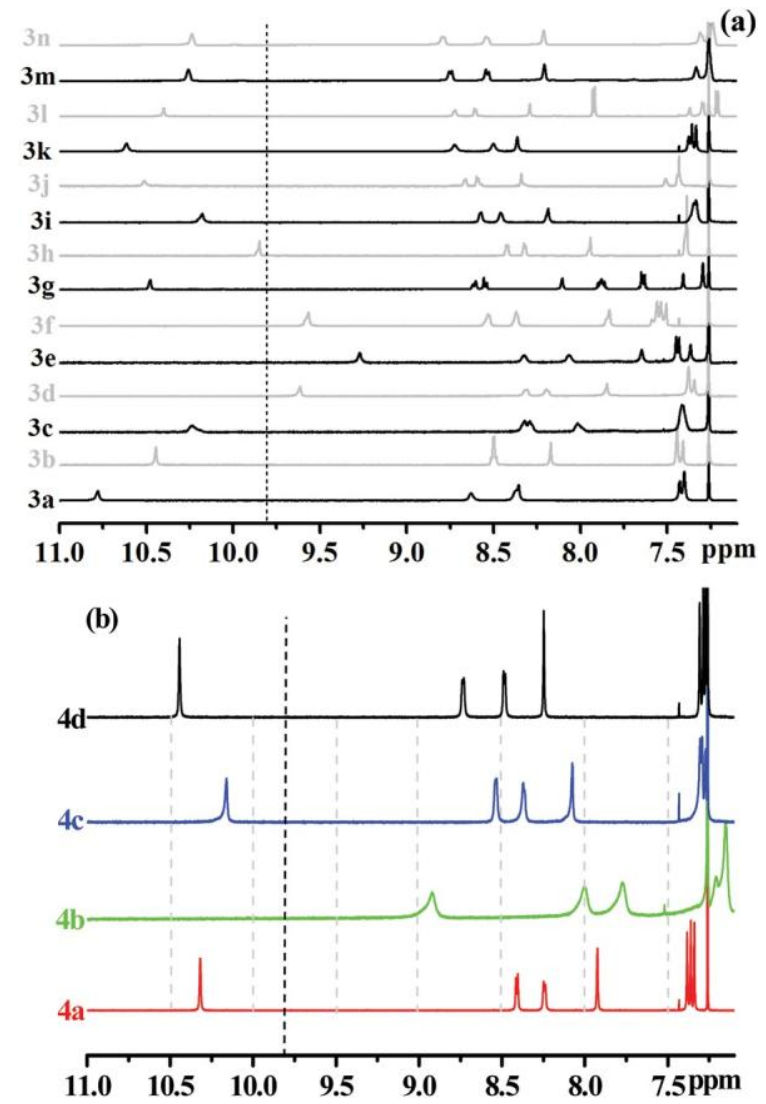

Fig. 1 Comparison of ${ }^{1} \mathrm{H}$ NMR spectra of the positively charged ionic DLCs 3 (a) and 4 (b); only aromatic regions showed for clarity; dashed lines is the chemical shift of proton $\mathrm{H} 1$ of 2 .

having lower $\mathrm{H}$-bonding ability with azatriphenylene $\mathrm{C}-\mathrm{H}(1)$ atom, the ${ }^{1} \mathrm{H}$ NMR spectra of compounds $3 \mathrm{~d}, 3 \mathrm{e}$, and $3 \mathrm{f}$ show upfield shifts of the signals of the hydrogen nuclei instead. Chemical shift displacements of compounds containing sulfones, sulfates, sulfonates (and nitrates) are comparable to $3 b$, but are still slightly deshielded with respect to signals of 2 . The same trend is observed for compounds of series 4 (Fig. 1b). These results thus coincide quite well with the trend observed in imidazolium- containing ionic liquids (Fig. 1). ${ }^{61}$

Decomposition analysis (TGA)

Humidity sensitivity and thermal stability are two important parameters for ionic liquid and thermotropic ionic liquid crystals. In particular, since salts 3 and 4 were synthesized by quaternization of the pyridine moiety, de-quaternization reaction is likely to occur on heating at high temperature by expelling the alkyl halide fragment, as previously reported. ${ }^{62}$

The decomposition or de-quaternization temperatures ( $\mathrm{T}_{\text {dec. }}$, defined as the onset temperature at $5 \mathrm{wt} \%$ weight-loss) of the synthesized organic salts, have been determined by TGA, and are gathered in Table S1 and shown in Fig. 4 and Fig. S2 (ESI †). They decompose over a broad range of temperatures, comprised between 262 and $3931 \mathrm{C}$ (temperature at 5\% loss). Compounds with small sized inorganic anions, $3 \mathrm{a}-\mathrm{c}\left(\mathrm{Br}, \mathrm{I}, \mathrm{NO}_{3}\right)$ and $4 \mathrm{a}(\mathrm{l})$ exhibit the lowest thermal stability, displaying $\mathrm{T}_{\mathrm{dec}}$. between 
262 and $2691 \mathrm{C}$, likely due to the above mentioned fast dequaternization and the subsequent release of the alkyl halide/ nitrate. In contrast, $3 \mathrm{f}$ and $4 \mathrm{~b}$, with the same highly stable bis(trifluoromethylsulfonyl)imide anion $\left(\mathrm{NTf}_{2}\right)$, exhibit the high- est thermal stability, with $\mathrm{T}_{\text {dec. }}$ at 390 and $3931 \mathrm{C}$, respectively. Replacement of the bromide ion with bulkier anions such as $\mathrm{PF}_{6}, \mathrm{BF}_{4}$ , $\mathrm{TfO}, \mathrm{NTf}_{2}, \mathrm{TsO}$ resulted in increasing thermal stability and high $\mathrm{T}_{\text {dec. }}(43301 \mathrm{C})$. The decomposition temperatures of the compounds with the large organic anions (i.e. alkylsulfonate, alkylsulfate, saccharinate, camphorsulfate) lie at intermediate values $\left(295 \mathbf{O} \mathrm{T}_{\text {dec. }} \mathbf{O}\right.$ $329 \mathrm{1C})$, consistent with reported pyridinium ionic LCs. From the experimental results listed above, the thermal stability of the iDLCs can be correlated with the nature of the anions. Indeed, due to the stronger ability of $\mathrm{Br}$ and $\mathrm{I}$ anions (and to a lesser extend $\mathrm{NO}_{3}$ ) to form hydrogen bonding, and thus their stronger basicity, thermal dealkylation reaction is much favoured for these compounds $(3 \mathrm{a}-\mathrm{c}$ and $4 \mathrm{a}$ ). On the contrary, de-alkylation reaction is less favoured for $3 \mathrm{~d}-\mathrm{f}$ and $4 \mathrm{~b}$ due to the weaker interactions of $\mathrm{BF}_{4}, \mathrm{PF}_{6}, \mathrm{Tf}_{2} \mathrm{~N}$ anions with the ionic aza- core, and therefore they exhibit higher thermal stability. Therefore, the anion interaction strength determines the thermal stability of these iDLCs: the stronger nucleophile the anion, the lower thermal stability the iDLC.

Investigation of the liquid-crystalline properties of the ionic discogens (POM, DSC, SAXS)

The liquid crystalline properties of 2 and salts $3 a-n$ and $4 a-d$ were investigated by polarizing optical microscopy (POM, Fig. 2 and Fig. S1, ESI†), differential scanning calorimetry (DSC, Fig. S3, ESI†)

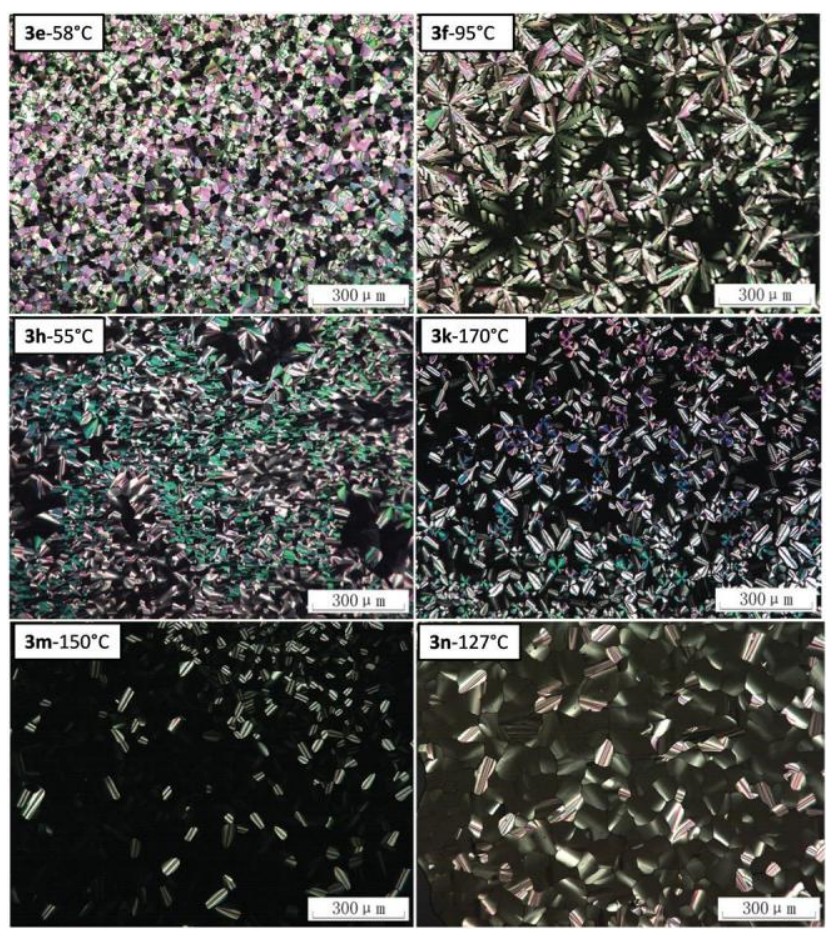

Fig. 2 Selection of typical optical textures of some representative iDLCs, obtained after slow cooling from the isotropic liquid into the mesophases.
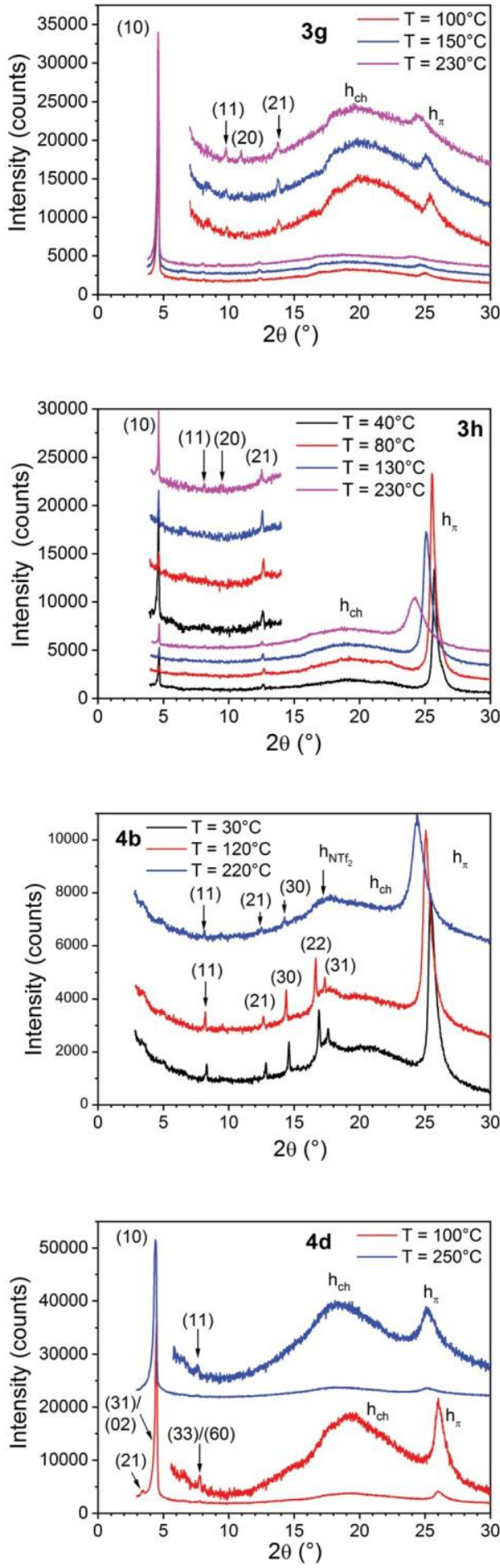

Fig. 3 SAXS patterns of four representative salts.

and small-angle X-ray scattering (SAXS, Fig. 3 and Fig. S4, ESI †). The phase transition temperatures and enthalpies are gathered in Table S2 $(E S I+)$ and mesophases' parameters and indexation are given in Table 1 and Table S3 (ESl†). Essentially all the ionic compounds display columnar mesophases, resulting from the stacking of the flat discoid cores (Fig. S8, DFT, ESI†) into columns, separated from each other by the aliphatic continuum. In con- trast, the neutral parent azatriphenylene 2 is non-mesomorphous 
Table 1 Geometrical parameters of the mesophases of salts 3 and $4^{\mathrm{a}}$

\begin{tabular}{|c|c|c|c|c|c|c|c|c|c|c|c|c|c|}
\hline Cpds & $\mathrm{T}$ & $\mathrm{V}_{\mathrm{mol}} / \mathbf{r}$ & Phase & Symmetry & $\mathrm{a}$ & $\mathrm{b}$ & $\mathrm{g}$ & A & $\mathrm{Z}$ & $A_{\text {mol }}$ & $\mathrm{h}_{\mathrm{mol}}$ & $\mathrm{h}_{\mathrm{p}}$ & $\mathrm{W}_{\mathrm{ch}}$ \\
\hline \multirow[t]{2}{*}{$3 b$} & 100 & $1301 / 1.07$ & $\mathrm{Col}_{\text {hex }}$ & p6mm & 21.06 & 21.06 & 120 & 384.0 & 1 & 384.0 & 3.39 & 3.48 & $0.65(9)$ \\
\hline & 130 & $1324 / 1.06$ & $\mathrm{Col}_{\text {hex }}$ & $\mathrm{p} 6 \mathrm{~mm}$ & 21.32 & 21.32 & 120 & 393.7 & 1 & 393.7 & 3.36 & 3.54 & $0.66(1)$ \\
\hline \multirow[t]{2}{*}{$3 e$} & 50 & $1309 / 1.09$ & $\mathrm{Col}_{\text {hex }}$ & p6mm & 22.06 & 22.06 & 120 & 421.4 & 1 & 421.4 & 3.11 & 3.55 & $0.63(2)$ \\
\hline & 80 & $1332 / 1.07$ & $\mathrm{Col}_{\text {hex }}$ & $\mathrm{p} 6 \mathrm{~mm}$ & 21.82 & 21.82 & 120 & 412.4 & 1 & 412.4 & 3.23 & 3.58 & $0.63(5)$ \\
\hline \multirow[t]{3}{*}{$3 \mathrm{f}$} & 60 & $1456 / 1.14$ & Hex & p3m1 & 21.71 & 21.71 & 120 & 408.2 & 1 & 408.2 & 3.57 & 3.62 & $0.56(5)$ \\
\hline & 120 & $1501 / 1.10$ & Hex & p3m1 & 21.89 & 21.89 & 120 & 415.0 & 1 & 415.0 & 3.62 & 3.69 & $0.57(9)$ \\
\hline & 180 & $1547 / 1.07$ & Hex & p3m1 & 21.85 & 21.85 & 120 & 413.5 & 1 & 413.5 & 3.74 & 3.81 & $0.58(6)$ \\
\hline \multirow[t]{3}{*}{$3 g$} & 100 & $1498 / 0.99$ & $\mathrm{Col}_{\text {hex }}$ & p6mm & 21.78 & 21.78 & 120 & 410.7 & 1 & 410.7 & 3.65 & 3.57 & $0.57(2)$ \\
\hline & 150 & $1536 / 0.97$ & $\mathrm{Col}_{\text {hex }}$ & $\mathrm{p} 6 \mathrm{~mm}$ & 21.85 & 21.85 & 120 & 413.3 & 1 & 413.3 & 3.71 & 3.62 & $0.57(8)$ \\
\hline & 230 & $1598 / 0.93$ & $\mathrm{Col}_{\text {hex }}$ & $\mathrm{p} 6 \mathrm{~mm}$ & 21.97 & 21.97 & 120 & 418.2 & 1 & 418.2 & 3.82 & 3.74 & $0.58(6)$ \\
\hline \multirow[t]{2}{*}{$3 h$} & 130 & $1394 / 1.03$ & $\mathrm{Col}_{\text {hex }}$ & $\mathrm{p} 6 \mathrm{~mm}$ & 21.53 & 21.53 & 120 & 401.4 & 1 & 401.4 & 3.47 & 3.55 & $0.62(8)$ \\
\hline & 230 & $1471 / 0.98$ & $\mathrm{Col}_{\text {hex }}$ & p6mm & 21.59 & 21.59 & 120 & 403.7 & 1 & 403.7 & 3.64 & 3.66 & $0.63(7)$ \\
\hline \multirow[t]{2}{*}{31} & 150 & $1479 / 1.00$ & $\mathrm{Col}_{\text {hex }}$ & $\mathrm{p} 6 \mathrm{~mm}$ & 22.25 & 22.25 & 120 & 428.8 & 1 & 428.8 & 3.45 & 3.52 & $0.60(0)$ \\
\hline & 250 & $1561 / 0.94$ & $\mathrm{Col}_{\text {hex }}$ & p6mm & 22.39 & 22.39 & 120 & 434.1 & 1 & 434.1 & 3.59 & 3.60 & $0.60(8)$ \\
\hline \multirow[t]{2}{*}{$3 \mathrm{~m}$} & 150 & $1563 / 1.01$ & $\mathrm{Col}_{\text {hex }}$ & $\mathrm{p} 6 \mathrm{~mm}$ & 21.92 & 21.92 & 120 & 416.0 & 1 & 416.0 & 3.76 & 3.54 & $0.56(8)$ \\
\hline & 250 & $1648 / 0.95$ & $\mathrm{Col}_{\text {hex }}$ & $\mathrm{p} 6 \mathrm{~mm}$ & 21.82 & 21.82 & 120 & 412.5 & 1 & 412.5 & 4.00 & 3.66 & $0.57(5)$ \\
\hline \multirow[t]{2}{*}{$3 n$} & 150 & $1563 / 1.01$ & $\mathrm{Col}_{\text {hex }}$ & $\mathrm{p} 6 \mathrm{~mm}$ & 22.10 & 22.10 & 120 & 423.0 & 1 & 423.0 & 3.69 & 3.59 & $0.56(8)$ \\
\hline & 250 & $1648 / 0.95$ & $\mathrm{Col}_{\text {hex }}$ & p6mm & 21.92 & 21.92 & 120 & 416.0 & 1 & 416.0 & 3.96 & 3.66 & $0.57(5)$ \\
\hline \multirow[t]{2}{*}{$3 \mathrm{i}$} & 120 & $1680 / 0.97$ & $\mathrm{Col}_{\text {hex }}$ & p6mm & 24.37 & 24.37 & 120 & 514.6 & 1 & 514.6 & 3.26 & 3.52 & $0.72(5)$ \\
\hline & 200 & $1760 / 0.92$ & $\mathrm{Col}_{\text {hex }}$ & p6mm & 24.34 & 24.34 & 120 & 513.1 & 1 & 513.1 & 3.43 & 3.63 & $0.73(1)$ \\
\hline \multirow[t]{2}{*}{$3 \mathrm{j}$} & 120 & $1664 / 0.96$ & $\mathrm{Col}_{\text {hex }}$ & p6mm & 23.59 & 23.59 & 120 & 481.9 & 1 & 481.9 & 3.45 & 3.51 & $0.73(2)$ \\
\hline & 230 & $1775 / 0.90$ & $\mathrm{Col}_{\text {hex }}$ & $\mathrm{p} 6 \mathrm{~mm}$ & 24.20 & 24.20 & 120 & 507.3 & 1 & 507.3 & 3.50 & 3.65 & $0.73(9)$ \\
\hline \multirow[t]{2}{*}{$3 \mathrm{k}$} & 150 & $1516 / 0.96$ & $\mathrm{Col}_{\text {hex }}$ & p6mm & 22.43 & 22.43 & 120 & 435.9 & 1 & 435.9 & 3.48 & 3.51 & $0.70(3)$ \\
\hline & 250 & $1605 / 0.91$ & $\mathrm{Col}_{\text {hex }}$ & $\mathrm{p} 6 \mathrm{~mm}$ & 22.55 & 22.55 & 120 & 440.4 & 1 & 440.4 & 3.64 & 3.67 & $0.70(9)$ \\
\hline \multirow[t]{3}{*}{$4 b$} & 30 & $1297 / 1.18$ & Hex & p3m1 & 21.00 & 21.00 & 120 & 381.9 & 1 & 381.9 & 3.39 & 3.50 & $0.52(5)$ \\
\hline & 120 & $1356 / 1.13$ & Hex & p3m1 & 21.32 & 21.32 & 120 & 393.6 & 1 & 393.6 & 3.45 & 3.55 & $0.53(5)$ \\
\hline & 220 & $1423 / 1.08$ & Hex & $\mathrm{p} 3 \mathrm{~m} 1$ & 21.58 & 21.32 & 120 & 403.3 & 1 & 403.3 & 3.53 & 3.64 & $0.54(5)$ \\
\hline \multirow[t]{2}{*}{$4 c$} & 90 & $1507 / 1.00$ & $\mathrm{Rec}_{\mathrm{pHex}}$ & $\mathrm{p} 2 \mathrm{mg}$ & 70.00 & 40.40 & 90 & 2827 & 6 & 471.2 & 3.20 & 3.50 & $0.69(7)$ \\
\hline & 150 & $1562 / 0.97$ & $\mathrm{Rec}_{\mathrm{pHex}}$ & $\mathrm{p} 2 \mathrm{mg}$ & 70.50 & 40.70 & 90 & 2869 & 6 & 478.2 & 3.27 & 3.53 & $0.70(1)$ \\
\hline \multirow[t]{3}{*}{$4 d$} & 30 & $1437 / 1.03$ & $\mathrm{Rec}_{\mathrm{pHex}}$ & $\mathrm{p} 2 \mathrm{mg}$ & 67.72 & 39.10 & 90 & 2647 & 6 & 441.2 & 3.26 & 3.38 & $0.69(5)$ \\
\hline & 100 & $1501 / 0.99$ & $\mathrm{Rec}_{\mathrm{pHex}}$ & p2mg & 68.38 & 39.48 & 90 & 2702 & 6 & 450.3 & 3.34 & 3.42 & $0.70(1)$ \\
\hline & 250 & $1637 / 0.91$ & $\mathrm{Col}_{\text {hex }}$ & p6mm & 23.20 & 23.20 & 120 & 466.0 & 1 & 466.0 & 3.51 & 3.53 & $0.71(5)$ \\
\hline
\end{tabular}

${ }^{a} \mathrm{~T}$, temperature of the SAXS measurement $(1 \mathrm{C}) ; \mathrm{V}_{\text {mol }}$, molecular volume $\left(\AA^{3}\right)$ and $\mathbf{r}$, density $\left(\mathrm{g} \mathrm{cm}^{3}\right)$; phase type $(\mathrm{Col}$ hex: hexagonal columnar phase, Hex: mesophase with hexagonal lattice, $R_{e} c_{p H e x}$ : mesophase with rectangular lattice of pseudo-hexagonal geometry $\left.(\mathrm{a} / \mathrm{b}=\mathrm{O} 3)\right)$ and lattice symmetry; $\mathrm{a}, \mathrm{b}$, g: mesophases' lattice parameters $(\AA$ and 1$) ; \mathrm{A}$, lattice area $\left(\AA^{2}\right) \mathrm{A}=\mathrm{a}^{2} \mathrm{O} 3 / 2$ for $\mathrm{Col}_{\text {hex }}$ and Hex phases, and $\mathrm{A}=\mathrm{a} \mathbf{x}$ b for Rec phases; $\mathrm{A}_{\text {mol }}$ : molecular area $\left(\AA^{2}\right)$ $A_{\text {mol }}=A / Z ; Z$ : number of columns per lattice; $h_{\text {mol }}$, molecular slice thickness $(\hat{A})$ with $h_{m o l}=V_{m o l} / A ; h_{p}$, stacking distance $(\AA) ; w_{c h}$, aliphatic volume fraction, $\mathrm{w}_{\mathrm{ch}}=\mathrm{V}_{\mathrm{ch}} / \mathrm{V}_{\mathrm{mol}}\left(\mathrm{V}_{\mathrm{ch}}\right.$, chain volume).

and shows a sharp crystal-to-isotropic transition at $1321 \mathrm{C}$. This behaviour may be due to the conjugated action of the low number of radiating aliphatic chains and the absence of stabilizing electrostatic interactions. In order to facilitate the following discussion and comparison of the thermal behaviour and LC properties of this large collection of ionic discotic compounds, the latter were subdivided into three main groups, differentiated by the total number of aliphatic chains surrounding the p-conjugated aromatic core, summing up those covalently linked to and radiating directly from the azatriphenylene moiety, and that brought by the ion pairs. We thus distinguish sets of mesogens with $6(3 \mathrm{i}-\mathrm{k}), 5(3 \mathrm{a}-\mathrm{h}, 1-\mathrm{n}, 4 \mathrm{c}-\mathrm{d})$ and 4 diverging chains $(4 \mathrm{a}$ and $4 \mathrm{~b})$, respectively; within the 5 -chain systems, we can further distinguish 3 sub-groups, those with inorganic $(3 a-e)$, organic $(3 \mathrm{f}-\mathrm{h}, \mathrm{l}-\mathrm{n})$ and lipophilic $(4 \mathrm{c}-\mathrm{d})$ counterions, respectively. The overall thermal behaviour of the compounds are represented in the phase diagram (Fig. 4). (i) The three mesogens with 6 chains (3i$\mathrm{k})$, whose sixth one is brought by the lipophilic anion, behave typically as their discotic hexakis(alkoxy)triphenylene homologues, except that mesomorphic properties extend to temperatures above 200 1C in presence of ions, compared to $971 \mathrm{C}$ for the hexyl DLC reference. ${ }^{63}$ The three iDLCs are indeed mesomorphous over

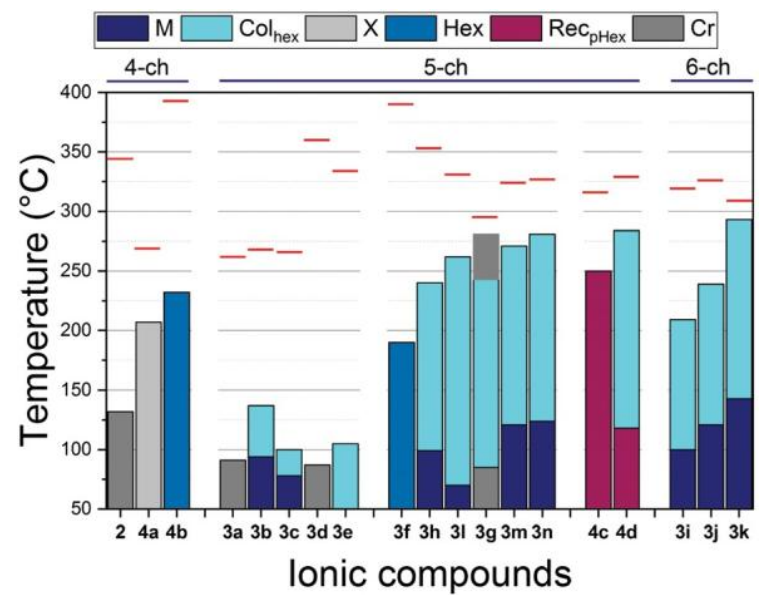

Fig. 4 Phase transition temperatures of iDLCs $(3 \mathrm{a}, 3 \mathrm{~d}$ and $3 \mathrm{k}$ : first heating cycle, 3g: crystalline range from 1st heating cycle (both in grey) and monotropic mesophase range (in cyan) from cooling cycle; all other salts: 2nd heating cycle). Red lines correspond to decomposition temperatures.

large temperature ranges (120-150 1C): the sulfonate derivative $3 \mathrm{j}$ has a slightly higher clearing temperature (ca. $240 \mathrm{lC}$ ) than its homologous dodecyl sulfate $3 \mathrm{i}$ (ca. 210 1C). In contrast, the 
derivative with the shorter chain of same length as the alkoxy substituents $(3 \mathrm{k})$ clears at much higher temperature, up to nearly $3001 \mathrm{C}$, following the trend reported for symmetrical vs. unsymmetrical hexakis(alkoxy)triphenylenes. ${ }^{64}$ On cooling from the isotropic liquid, they display birefringent fan-shaped textures within large homeotropic areas, characteristic of the hexagonal columnar phase (Fig. 2 and Fig. S1, ESI†). DSC also reveals an additional phase transition at lower temperature, undetectable by POM. The SAXS patterns of the 3 compounds were recorded at various temperatures (Fig. S4, ESI $\dagger$ ), and all exhibit the characteristic features of a two-dimensional colum-

nar hexagonal phase, in agreement with POM observations. In the wide-angle range, two broad scattering signals were system- atically present, emerging respectively from the average lateral distances between molten chains ( $\mathrm{h}_{\mathrm{ch}}$ E 4.5-4.7 $\AA$ ) and from the stacking periodicities between the flat mesogenic cores piled into columns $\left(h_{p} \quad\right.$ E 3.5-3.7 $\left.\AA\right)$; although the broadness of the latter signal indicates that the nearly orthogonal stacking is short-range. In the small-angle range, the presence of one strong first-order reflection (10) and up to three weakly-intense supplementary reflections, according to spacing ratios $\mathrm{O} 3,2, \mathrm{O} 7$ and indexed as $(\mathrm{hk})=(11),(20)$ and (21) (Table S3, ESI $\dagger$ ), confirms in all cases the formation of long-range two- dimensional hexagonal lattice with one single column, with well- defined interfaces between the piled cores and the surrounding chains. The low-temperature phase(s) labelled as $\mathrm{M}$ (and $\mathrm{M}^{0}$ ) detected by DSC, showed very similar SAXS patterns (but with supplementary mid- and wide-angle rising peaks, displacement of the wide-angle diffusion to smaller angles, and/or broadening of the fundamental reflection) suggesting that they must retain the main features of the above fluid mesophase, with locally preserved columnar structuration. These intermediate stable states likely result from the stiffening and even partial crystallization of the aliphatic chains concomitant to an enhanced stacking due to some possible slight re-organization of the counterions around the aromatic cores.

(ii) All compounds with 5 chains and small inorganic anions ( $3 \mathrm{a}-$ e), but salts $3 \mathrm{a}(\mathrm{Br})$ and $3 \mathrm{~d}\left(\mathrm{BF}_{4}\right)$, exhibit enantiotropic mesophases, over small temperature ranges (Table S2, ESI $\dagger$ ), with a maximum clearing temperature of $137 \mathrm{1C}$ for $3 \mathrm{~b}$. The reduction to five radiating chains combined with small anions results in the drastic diminution of phase stability by more than $1001 \mathrm{C}$ with respect to the previous series. As observed by POM, the mesomorphous compounds displayed a wide range of characteristic optical textures of hexagonal columnar meso-phases e.g. fan-shaped, long linear defects and large homeo- tropic domains (Fig. 2 and Fig. S1, ESl + ). The absence of LC properties for $3 \mathrm{a}$ and $3 \mathrm{~d}$ might be due to the peculiarities of both $\mathrm{Br}$ and $\mathrm{BF}_{4}$ anions. ${ }^{17}$ For salt $3 \mathrm{a}$, only one transition was seen during the first heating run corresponding to melting from the crystalline state into the isotropic liquid. On cooling from the isotropic liquid, no sign of crystallization was detected, even at room temperature after several weeks, meaning that this salt behaves as a true ionic liquid. For $3 \mathrm{~d}$, the absence of LC properties, may be due to tendency of $\mathrm{BF}_{4}$ to have closer contact with the $\mathrm{N}$-atom, even to intercalate between successive discs, disturbing substantially the $\mathrm{p}-\mathrm{p}$ stacking of the aromatic cores into columns. SAXS measurements, recorded for $3 \mathrm{~b}$ and $3 \mathrm{e}$ only $3 \mathrm{c}$ showed extensive decomposition upon exposure to the X-ray beam while in the mesophase), confirmed the self-assembling into columnar hexagonal mesophases $\left(\mathrm{Col}_{\text {hex }}\right)$, as characterized by the two strong wide-angle scattering signals, $h_{c h}\left(\begin{array}{lll}E & \AA & \AA\end{array}\right)$ and $h_{p}$ $($ E3.5-3.6 $\AA$ ), and by the intense small-angle funda- mental reflection (10). Similarly to the 6-chain compounds, a lowtemperature mesophase, M, was also detected by DSC, which similarly retains the principal organization of the $\mathrm{Col}_{\text {hex }}$ mesophase, as revealed by SAXS (Fig. S4, ESI $\dagger$ ).

(iii) The ion exchange with the more voluminous triflate $(3 \mathrm{~h})$, bis(trifluoromethylsulfonyl)imide (3f), tosylate (31), saccharinate $(3 \mathrm{~g})$ and camphorsulfate $(3 \mathrm{~m}, 3 \mathrm{n})$ anions resulted overall in a substantial enhancement of the mesomorphic temperature ranges and phase stabilities, similarly to the results obtained after the substitution with lipophilic anion in the 6-chain derivatives $(3 \mathrm{i}-\mathrm{k})$. The congestion of the saccharinate moiety however nevertheless destabilizes the mesomorphism in $3 \mathrm{~g}$, which only occurs on cooling from the isotropic liquid (mono- tropic behaviour). Apart for $3 \mathrm{~g}$ and the $\mathrm{Tf}_{2} \mathrm{~N}$ compound $3 \mathrm{f}$, which has the lowest clearing (below $2001 \mathrm{C}$ ), the behaviour of the other terms of this series is more or less constant with clearing temperatures fluctuating around $250 \pm 301 \mathrm{C}$, the higher ones for the camphorsulfate derivatives. Optical textures presented broken fan shapes (3f, 3h) hexagonal dendritic domains and fernlike texture $(3 \mathrm{~g})$, and fan-shaped defects (31,

$3 \mathrm{~m}$ and $3 \mathrm{n}$ ) and systematically large homeotropic domains for all, all characteristic features of the hexagonal columnar phase (Fig. 2 and Fig. S1, ESI + ). The SAXS patterns of $3 \mathrm{~g}, 31,3 \mathrm{~m}$ and $3 \mathrm{n}$ turned out to be similar and displayed classical patterns of a hexagonal columnar structure, as for the 6-chain compounds discussed above. All presented the broad scattering $h_{\text {ch }}(4.5-4.8 \AA)$ and the semidiffuse scattering $h_{p}(3.5-3.7 \AA)$ signals. In the small-angle range, a very intense fundamental reflection (10) was systematically observed, along with up to 4 higher-order reflections, indexed as (11), (20) and (21), for $3 \mathrm{~g}$ and 31, or only one higher-order reflection, indexed as (21), for $3 \mathrm{~m}$ and $3 \mathrm{n}$. As observed above, the lowtemperature mesophase $\mathrm{M}$ is no more fluid and is a structural reminiscence of the hexagonal phase. The two compounds with highly-fluorinated counterion (3f, 3h) however showed SAXS patterns of different appearance, though still in agreement with hexagonal symmetry. SAXS pattern of $3 \mathrm{~h}$ (Fig. 3) revealed a sharp but weakly intense fundamental (10) reflection, along three weak additional peaks $((11),(20)$, and $(21))$, the broad scattering $\left(\mathrm{h}_{\mathrm{ch}}\right)$ and the only slightly broadened and very intense periodicity $\left(\mathrm{h}_{\mathrm{p}}\right)$ corresponding to a regular and cohesive stacking of the cores. This pattern is still in agreement with classical $\mathrm{Col}_{\text {hex }}$ configuration, i.e. with columns of stacked mesogens at lattice nodes, separated by peripheral continuum of molten chains. The only particularity is that the $\mathrm{TfO}$ counterions distribute randomly around columns with the high electron-density $\mathrm{CF}_{3}$ groups protruding in the aliphatic continuum. The average electronic density of the continuum is therefore elevated and the contrast with columns thus reduced, which explains the exhaustion of the (10) reflection. For $3 \mathrm{f}$, the 
fundamental reflection (10) and the first higher-order reflection (11) even totally vanished in the SAXS pattern, leaving only a set of 4 small-angle, sharp but weakly intense, high-order reflec- tions, (21), (30), (22) and (31), the last two only seen at low temperature. The missing low-angle reflections, together with the maintenance of a single-column lattice area, reveal that the counterions are not any more randomly distributed but gen- erate a peak of electronic density at defined positions between columns. Indeed, triflimide is rather voluminous, and actually corresponds to almost $2 / 3$ of the azatriphenylene disc volume, so that the stacking process necessarily involves interactions between counterions. Consistently, a scattering signature of the packing within triflimide domains $\left(\mathrm{h}_{\mathrm{NTf2}}\right)$ is seen in the wide- angle region (maximum at roughly $5.5 \AA$ ), next to the scattering signals of triphenylene stacking $\left(h_{p}\right)$ and molten chain packing $\left(h_{c h}\right)$. This configuration has more structural features than a genuine $\mathrm{Col}_{\text {hex }}$ mesophase and was hence assigned to a "meso- phase with two-dimensional hexagonal structure" (Hex).

(iv) The last two compounds with 5 chains, $4 \mathrm{c}$ and $4 \mathrm{~d}$, show similarly wide-temperature range mesophases, from room temperature up to $2501 \mathrm{C}$ and $2801 \mathrm{C}$, respectively. Their optical textures were uncharacteristic (Fig. S1, ESI†), and not suffi ciently specific to identify the mesophase. Columnar-like mesomorphism was confirmed by SAXS (Fig. 3 and Fig. S4, ESI†). The wide-angle range was similar as described above (broad $h_{c h}$ scattering and intense and only slightly broadened $h_{p}$ peak) in agreement with cohesive and regular stacking of the cores into columns. The various sharp reflections measured in the smallangle range were indexed according to a non-centred rectangular symmetry of pseudo-hegagonal geometry, i.e. with lattice parameter ratio $\mathrm{a} / \mathrm{b}=\mathrm{O} 3$ (Table S3, ESI + ). The missing fundamental reflections (11)/(20) and the large size of the lattice indicate a multisegregated arrangement with several columns per lattice, assigned to a "mesophase with rectangular pseudohexagonal structure" $\left(\mathrm{Rec}_{\mathrm{pHex}}\right)$. On increasing the temperature above $1181 \mathrm{C}$, the small-angle part of the SAXS pattern of $4 \mathrm{~d}$ transformed, in agreement with the transition into another mesophase (as observed by DSC). The small reflection (21) of the low-temperature phase disappears, allowing the indexation of the intense reflection as (10) and the small one as (11) of a hexagonal lattice, and thus to the formation of a $\mathrm{Col}_{\text {hex }}$ phase.

(v) The last mesogens of this series of compounds, $4 \mathrm{a}$ and $4 \mathrm{~b}$, possess only 4 chains. Unlike the neutral precursor, both display wide-range mesophases, with clearing above $2001 \mathrm{C}$. The textures of $4 \mathrm{a}$ and $4 \mathrm{~b}$ were rather uncharacteristic (Fig. S1, ESI $\dagger$ ) and the nature of the mesophases could not be estab- lished at this stage by this technique only. Compound 4a could unfortunately not be analysed further due to extremely fast degradation upon exposure to X-ray sources, even at low temperatures (See TGA, Fig. S2, ESI†), and thus the mesophase could not be ultimately identified. The SAXS pattern of $4 \mathrm{~b}$ was however almost identical to that of the other triflimide- containing salt $3 \mathrm{f}$ discussed above. Indeed, the SAXS pattern revealed a set of 5 small-angle high-order reflections of a hexagonal lattice, sharp and weakly intense, (11), (21), (30), (22) and (31), the last two disappearing upon temperature increase. In addition to the broad scattering of the molten chains $\left(h_{c h}\right)$ and the intense reflection corresponding to the stacking periodicity $\left(\mathrm{h}_{\mathrm{p}}\right)$ that associated to the bulky triflimide moiety $\left(\mathrm{h}_{\mathrm{NTt2}}\right)$ was clearly seen. The missing fundamental reflection (10), the lattice size and the presence of $h_{\mathrm{NTf2}}$ therefore confirm the same three-domain Hex structure for $4 \mathrm{~b}$ as for 3f. The supramolecular organization of all the compounds will be discussed in the next section.

Supramolecular organization in the mesophases

Most compounds with 5 and 6 side-chains, and in particular those with of a longer chain on the quaternized azatriphenylene cores (Atph) and relatively small counterions, self-assemble in $\mathrm{Col}_{\text {hex }}$ mesophases. The average structure consists in p6mm arrangement of cylindrical columns spaced by a continuum (Fig. 5), which implies that the nearly-discoid rigid cores adopt various orientations along the stacking direction to allow a homogeneous distribution of the aliphatic chains and counter- anions in their periphery. The values of $h_{\text {mol }}$ (columnar slice thickness calculated from the ratio between the molecular volume, $\mathrm{V}_{\mathrm{mol}}$, and the molecular area, $\mathrm{A}_{\mathrm{mol}}$, Table 1) for $3 \mathrm{f}-\mathrm{h}, 31-\mathrm{n}, 3 \mathrm{i}-\mathrm{k}$ are very comparable to $\mathrm{h}_{\mathrm{p}}$ (with a maximum discrepancy of $\pm 0.2 \AA$ ), and compatible with the nearly orthogonal stacking of the cores within the columns (i.e. without tilt or only small tilt angles of the cores due to thermal fluctuations). These iDLCs therefore self-assemble just in the same way as the parent hexa- substituted DLCs, except that the aliphatic continuum incor-porates the counterions. The ionic interactions with Atph columns however considerably reinforce the cohesion of the stacking and lead to mesomorphic range extensions between 100 and $2001 \mathrm{C}$ relatively to reference DLCs. For series 4 , the self-assembly process yields different structures, obviously

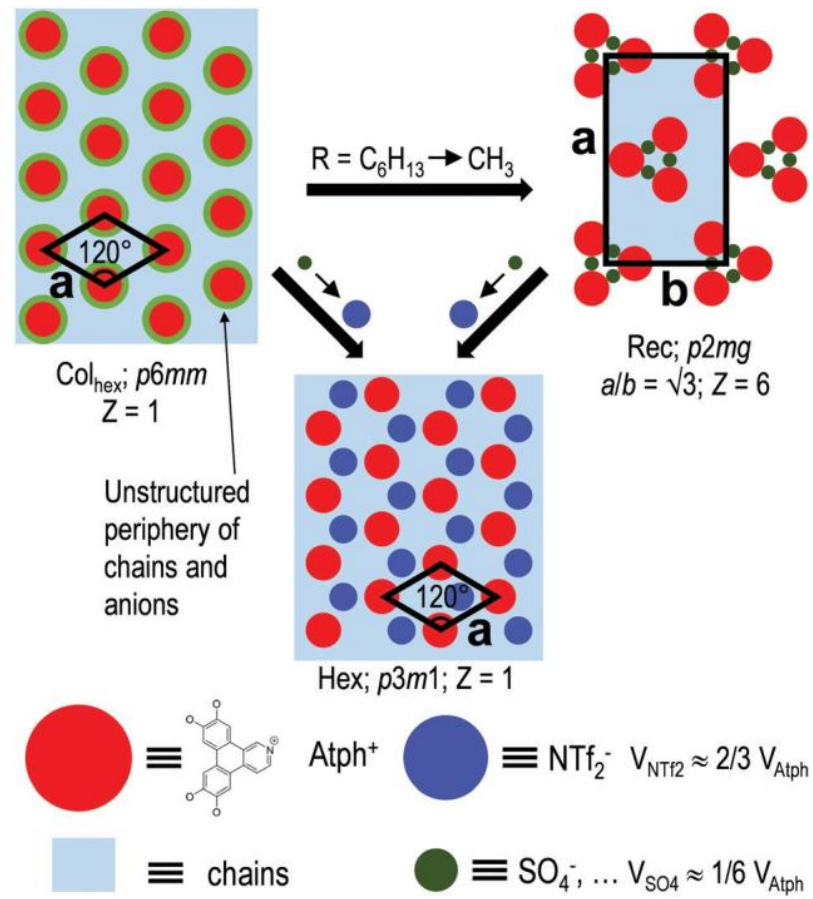

Fig. 5 Schematic views of the likely supramolecular organizations. 
because the replacement of the longer chain by a methyl group authorizes neighbouring columns to move closer. For $4 \mathrm{c}-\mathrm{d}$, this proximity leads to a large-size lattice $\mathrm{Rec}_{\mathrm{pHex}}$ phase following the bridging of the columns by the counterions and the arrangement of the so-formed clusters into a rectangular, noncentred lattice. Lattice size, pseudo-hexagonal geometry and intensity variation in the reflection series indicate a herringbone alignment of clusters of 3 bridged columns, the likely arrangement of p2mg symmetry being schematically represented in Fig. 5. The structural features are essentially the $\begin{array}{lll}\text { same for the } \mathrm{OSO}_{3} & \text { (4c) and } \mathrm{SO}_{3} & \text { (4d) anionic heads, but the }\end{array}$ cohesion of the clusters are considerably lower for $\mathrm{SO}_{3}$ as they dissociate at $118 \mathrm{1C}$ on crossing the transition to the $\mathrm{Col}_{\text {hex }}$ phase. The $\mathrm{Rec}_{\mathrm{pHex}}$ phase of $4 \mathrm{c}$ is on the contrary maintained up to the clearing point around $250 \mathrm{1C}$. The reason for this early dissociation of $\mathrm{SO}_{3}$-bridged clusters might be the smaller size of the anion, which increases steric constrains from crowded chains.

In any event, the anion size is determinant for the supramolecular organization, and $3 \mathrm{f} / 4 \mathrm{~b}$ with the bulkier $\mathrm{NTf}_{2}$ give a structure, which is diff erent from the other terms of the series. Triflimide is indeed too bulky anion to be drown in the aliphatic periphery as typical in series 3 or to bridge neighbouring columns into compact clusters as observed for $4 \mathrm{c}-\mathrm{d}$. Instead, the anions interact and self-assemble to individual domains, forming a multi- segregated arrangement with intermingled triphenylene columns and molten chains zones. Thanks to the favourable stoichiometry and partial volume ratios, this structure complies with the ideal case of a honeycomb-like lattice with alternation of triflimide domains and Atph columns at lattice nodes and molten chains zones at lattice centres (Fig. 5). With respect to $\mathrm{Col}_{\text {hex }}$, this Hex structure preserves the hexagonal geometry and the single-column lattice periodicity, but the symmetry is reduced to $\mathrm{p} 3 \mathrm{~m} 1$. It should be noticed that the longer chain or the methyl group on Atph does

not drive the self-assembling as for the other terms of the series; there is only a small impact on mesomorphic range width due to the swelling of aliphatic zones at honeycomb centres.

Photophysical properties of azatriphenylene and quaternized ionic discotic liquid crystal salts derivatives - UV/Vis absorption and photoluminescence properties

The optical properties were studied by UV-Vis absorption and photoluminescence spectroscopy in dilute THF solutions and in thin films (Table 2 and Fig. 6). Absorption spectra for all com- pounds are given in Fig. 6a. As can be seen, in dilute solutions $\left(10{ }^{5} \mathrm{~mol} \cdot \mathrm{L}\right.$ $\left.{ }^{1}\right)$, the absorption spectra of all the ionic compounds

are fully superimposable in the UV-Vis range, whatever the type of counteranion and the number and length of the side-chains, and show a unique strong absorption broad band with a maximum at $292 \mathrm{~nm}$, originated from the $\mathrm{p}-\mathrm{p}^{*}$ transition (see DFT calculations in ESI†), typical of charged dibenzo[f,h]isoquinoline species. Upon quaternization, the absorption of 2 is then redshifted by about $20 \mathrm{~nm}$ (Table 2).

Whereas 2 shows blue fluorescence in THF solution, all the salts exhibit yellow fluorescence (Fig. 6 and Fig. S5, ESI†) with maxima centered around 525-533 $\mathrm{nm}$. These minor changes imply that the excited states of the compounds are not greatly affected by anions and the length of the N-substituents. The fluorescent efficiency (quantum yield, QY) was measured with solution concentration of 1 x $10^{5}$ mol $L^{1}$ in THF for all compounds: 2 displayed high quantum yields, about $75 \%$ (at an excitation wavelength of $310 \mathrm{~nm}$ ). Salt 3 a displays the lowest quantum yield of emission, with an efficiency of about $2 \%$ (at $335 \mathrm{~nm}$ ), whereas salt $3 \mathrm{~d}$ shows the highest photoluminescence, with an efficiency of about $22 \%$ (at $360 \mathrm{~nm}$ ).

The fluorescent properties of thin film were also studied by using solution-cast films from THF onto quartz plates (Fig. S6, ESli). Each of them with the exception of $4 \mathrm{a}$ and $3 \mathrm{~b}$ showed one broad and intense peak maxima centered between 500 and $549 \mathrm{~nm}$ when excited at $335 \mathrm{~nm}$ (Fig. 6). The light-emission

Table 2 Photo-physical properties of the synthesized azatriphenylene 2 and its salts 3 and $4^{\mathrm{a}}$

\begin{tabular}{|c|c|c|c|c|c|}
\hline Cpds & $\mathbf{1}_{\mathrm{abs}}(\mathrm{nm})$ & $\mathrm{e}\left(\mathrm{x} 10^{4}, \mathrm{~L} \mathrm{~mol} \mathrm{~cm}^{1}\right)$ & $\mathbf{1}_{\mathrm{em}}$ solution $(\mathrm{nm})$ & $\mathbf{1}_{\mathrm{em}}$ film $(\mathrm{nm})$ & Quantum yield QYa [\%] \\
\hline $2, \mathrm{D}$ & 275 & 10 & 397 & - & 75.3 \\
\hline $3 \mathrm{a},\left[\mathrm{HexD}^{+}\right][\mathrm{Br}]$ & 292 & 10 & 529 & 537 & 2.0 \\
\hline $3 b,\left[\operatorname{HexD}^{+}\right][1]$ & 292 & 10 & 530 & - & 1.7 \\
\hline $3 \mathrm{c},[\mathrm{HexD}+]\left[\mathrm{NO}_{3}\right]$ & 292 & 10 & 529 & 543 & 21.3 \\
\hline $3 \mathrm{~d},\left[\mathrm{HexD}^{+}\right]\left[\mathrm{BF}_{4}\right]$ & 292 & 9.98 & 527 & 546 & 21.8 \\
\hline $3 \mathrm{e},[\mathrm{HexD}]\left[\mathrm{PF}_{6}\right]$ & 292 & 10 & 533 & 547 & 20.0 \\
\hline $3 \mathrm{f},\left[\mathrm{HexD}^{+}\right]\left[\mathrm{Tf}_{2} \mathrm{~N}\right]$ & 292 & 9.96 & 531 & 538 & 19.3 \\
\hline $3 \mathrm{~g},\left[\mathrm{HexD}^{+}\right][\mathrm{Sac}]$ & 292 & 10 & 528 & 533 & 17.9 \\
\hline $3 \mathrm{~h},\left[\mathrm{HexD}^{+}\right][\mathrm{TfO}]$ & 292 & 9.99 & 529 & 509 & 21.5 \\
\hline $3 \mathrm{i},[\mathrm{HexD}]\left[\mathrm{C}_{12} \mathrm{H}_{25} \mathrm{OSO}_{3}\right]$ & 292 & 10 & 526 & 520 & 20.3 \\
\hline $3 \mathrm{j},[\mathrm{HexD}]\left[\mathrm{C}_{12} \mathrm{H}_{25} \mathrm{SO}_{3}\right]$ & 292 & 10 & 528 & 504 & 14.6 \\
\hline $3 \mathrm{k},\left[\mathrm{HexD}^{+}\right]\left[\mathrm{C}_{6} \mathrm{H}_{13} \mathrm{SO}_{3}\right.$ & 292 & 10 & 526 & 520 & 17.6 \\
\hline 31, [HexD+][TsO ] & 292 & 10 & 527 & 500 & 15.3 \\
\hline $3 \mathrm{~m},\left[\mathrm{HexD^{+ }}\right][\mathrm{L}-\mathrm{CS}]$ & 292 & 9.94 & 531 & 516 & 18.7 \\
\hline $3 \mathrm{n},\left[\mathrm{HexD}^{+}\right][\mathrm{D}-\mathrm{CS}]$ & 292 & 9.96 & 532 & 520 & 20.6 \\
\hline $4 \mathrm{a},\left[\mathrm{MeD}^{+}\right][\mathrm{i}]$ & 292 & 10 & 533 & - & 3.0 \\
\hline $4 \mathrm{~b},\left[\mathrm{MeD}^{+}\right]\left[\mathrm{Tf}_{2} \mathrm{~N}\right]$ & 292 & 10 & 536 & 549 & 19.2 \\
\hline $4 \mathrm{c},\left[\mathrm{MeD}^{+}\right]\left[\mathrm{C}_{12} \mathrm{H}_{25} \mathrm{OSO}_{3}\right]$ & 292 & 10 & 525 & 529 & 22.4 \\
\hline $4 \mathrm{~d},\left[\mathrm{MeD}^{+}\right]\left[\mathrm{C}_{12} \mathrm{H}_{25} \mathrm{SO}_{3}\right]$ & 292 & 9.98 & 533 & 526 & 18.4 \\
\hline
\end{tabular}

a Fluorescence spectra were measured at $\mathbf{1}_{\text {exc }}=335 \mathrm{~nm}$. Fluorescence absolute quantum yield of salts was measured with solution concentration of $1 \times 10^{5} \mathrm{~mol} \mathrm{~L}^{1}$ in THF excited at $360 \mathrm{~nm}$ (neutral azatriphenylene 2 excited at $310 \mathrm{~nm}$ ). 

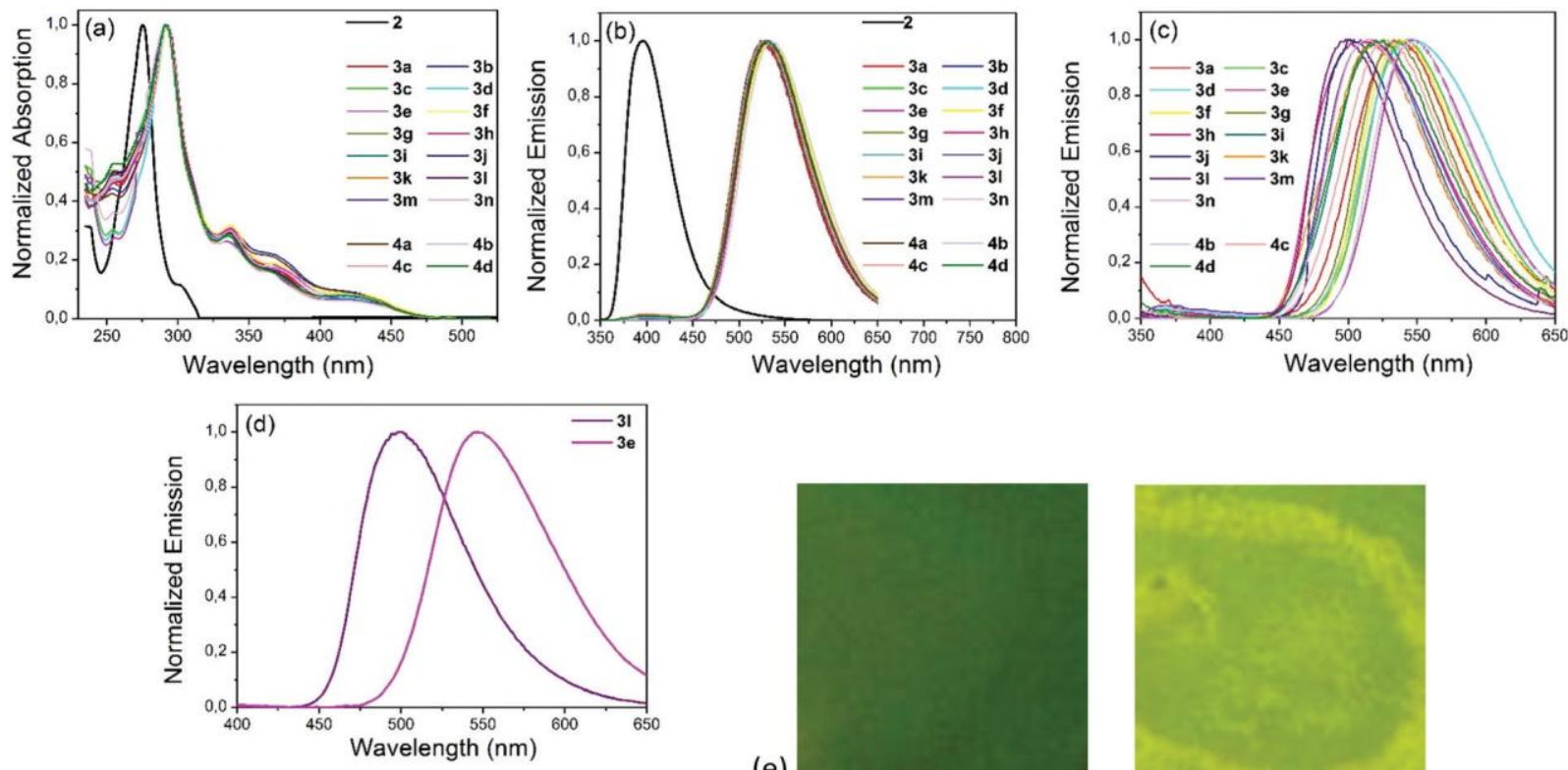

(e)
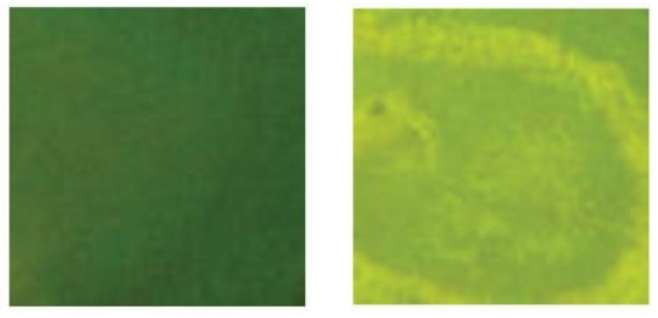

Fig. 6 (a) UV/Vis absorption spectra; (b) photoluminescence in dilute solution; (c) photoluminescence in thin-films; (d and e) selected photolumines- cence spectra and photographs in thin-films of two typical compounds; the photographs were taken under UV light ( $365 \mathrm{~nm})$ irradiation in the thin-films at room temperature. $31(\mathrm{TsO}, 500 \mathrm{~nm}), 3 \mathrm{e}\left(\mathrm{PF}_{6}, 547 \mathrm{~nm}\right)$.

from $4 \mathrm{a}$ and $3 \mathrm{~b}$ was too weak to be measured because of the occurrence of quenching. The thin film emission spectra of some compounds displayed a red shift, when compared with those of solution spectra, indicating more ordered structures formation in the stacking of aromatic rings in the solid states, whereas some compounds displayed a blue shift, when compared with their emission in solution. Emission from solid films are far more depending on the intermolecular aggregation behaviour determined here by the anion size and geometry, and the strength of electrostatic interactions These results support $\mathrm{p}$-p-like aggregation of the ionic azatriphenylene core in thin films. This unexpected anion selectivity could be leveraged in various potential applications as organic fluorescent sensors and opto- electronic materials (Fig. 7).

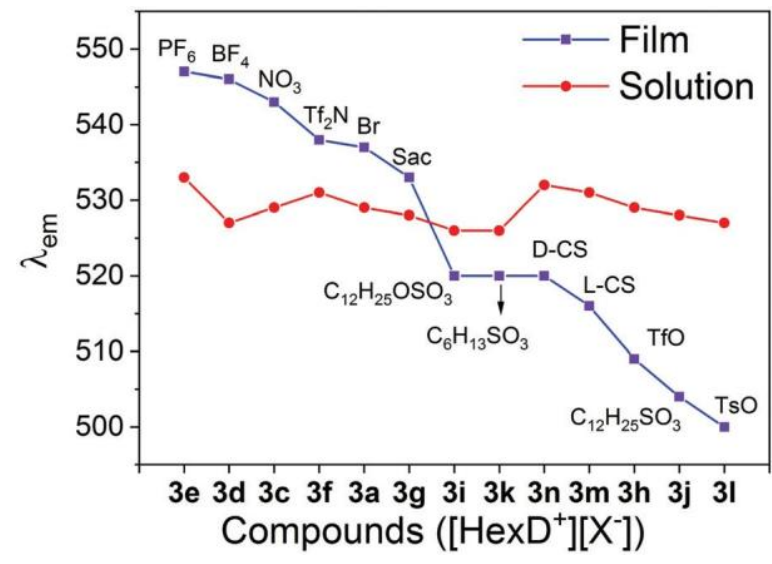

Fig. 7 Comparison of the photoluminescence in thin films and solution for compounds of series 3 , as a function of the counterion $X$.
These original photophysical results also revealed that neutral dibenzo[ f,h]isoquinoline 2 and corresponding ionic dibenzo[ $\mathrm{f}, \mathrm{h}$ ]isoquinolin-2-ium derivatives 3 and 4 represent a new and inter- esting type of luminophore and luminescent organic salts, con- stituted of $p$ conjugated heterocyclic aromatic hydrocarbon ionic unit, with absolute emission quantum yields above $20 \%$.

\section{Conclusions}

A novel heterocyclic azatriphenylene polycyclic aromatic hydrocarbon 2 was obtained in good yields from readily accessible precursors by Suzuki-Miyaura cross-coupling reaction and $\mathrm{FeCl}_{3}$ oxidative Scholl cyclodehydrogenation reaction. Quaternization of 2 by metathesis reaction with various salts, led to a collection of 18 ionic DLCs. POM, DSC and SAXS results revealed that most salts exhibit broad temperature range of $\mathrm{p} 6 \mathrm{~mm}-\mathrm{Col}_{\text {hex }}$ meso- phase; two compounds of the series 4 exhibit a mesophase with an arrangement of column and counterion clusters according to a rectangular lattice of pseudo-hexagonal geometry (i.e. $\mathrm{a} / \mathrm{b}=\mathrm{O} 3$ ) and $\mathrm{p} 2 \mathrm{mg}$ symmetry, whereas the triflimide-containing com- pounds give a mesophase with a honeycomb-like lattice of $\mathrm{p} 3 \mathrm{~m} 1$ symmetry (Hex). The thermal stability of these ionic DLC is high in most cases, with decomposition temperatures between

262-393 1C and a strong anion-dependence. The optical properties displayed UV/Vis absorption and anion-selective luminescence with wavelength in the range $500-550 \mathrm{~nm}$, with quantum yield as high as $20 \%$, while azatriphenylene 2 as a novel blue luminophore displays absolute quantum yield of $75 \%$. Azatriphenylene-based ionic compounds have the potential to become a workhorse of ionic DLCs, and this scaffold can be further tuned by ionic self-assembly for polarizing luminescence, anionic sensors, and ordered ion and electron transport materials. 


\section{Conflicts of interest}

There are no conflicts to declare.

\section{Acknowledgements}

This research was financially supported by the National Natural Science Foundation of China (NSFC, Fund numbers: 21772135, $51273133,51773140)$. BD and BH thank CNRS and University of Strasbourg for support.

\section{References}

1 N. V. Plechkova and K. R. Seddon, Chem. Soc. Rev., 2008, 37, 123-150.

2 S. P. M. Ventura, F. A. Silva, M. V. Quental, D. Mondal, M. G. Freire and J. A. P. Coutinho, Chem. Rev., 2017, 117, 6984-7052.

3 S. Zeng, X. Zhang, L. Bai, X. Zhang, H. Wang, J. Wang, D. Bao, M. Li, X. Liu and S. Zhang, Chem. Rev., 2017, 117, 9625-9673.

4 Q. Zhang and J. M. Shreeve, Chem. Rev., 2014, 114, 10527-10574.

5 (a) D. Adam, P. Schuhmacher, J. Simmerer, L. Haussling, K. Siemensmeyer, K. H. Etzbachi, H. Ringsdorf and D. Haarer, Nature, 1994, 371, 141-143; (b) A. V. D. Craats, J. Warman, A. Fechtenkäter, J. D. Brand, M. Harbison and K. Mülen, Adv. Mater., 1999, 11, 1469-1472; (c) H. lino, J. Hanna, R. J. Bushby, B. Movaghar, B. J. Whitaker and M. J. Cook, Appl. Phys. Lett., 2005, 87, 132102; (d) K. Q. Zhao, C. Chen, H. Monobe, P. Hu, B. Q. Wang and Y. Shimizu, Chem. Commun., 2011, 47, 6290-6292.

6 T. Wöhrle, I. Wurzbach, J. Kirres, A. Kostidou, N. Kapernaum, J. Litterscheidt, J. C. Haenle, P. Staff eld, A. Baro, F. Giesselmann and S. Laschat, Chem. Rev., 2016, 116, 1139-1241.

7 S. Sergeyev, W. Pisula and Y. H. Geerts, Chem. Soc. Rev., 2007, 36, 1902-1929.

8 Y. Shimizu, K. Oikawa, K. Nakayama and D. Guillon, J. Mater. Chem., 2007, 17, 4223-4229.

9 (a) M. O'Neill and S. M. Kelly, Adv. Mater., 2003, 15, 1135-1146; (b) A. Mishra, C.-Q. Ma and P. Bäuerle, Chem. Rev., 2009, 109, 1141-1276.

10 R. J. Bushby, S. M. Kelly and M. O'Neill, Liquid Crystalline Semiconductors: Materials, Properties and Applications, Springer Series in Materials Science. Springer Dordrecht Heidelberg, New York London, 2013, vol. 169.

11 (a) M. Funahashi and J. Hanna, Phys. Rev. Lett., 1997, 78, 2184-2187; (b) M. Funahashi and J. Hanna, Appl. Phys. Lett., 2000, 76, 2574-2576; (c) H. lino and J. Hanna, Adv. Mater., 2011, 23, 1748-1751; (d) H. lino, T. Usui and J.-I. Hanna, Nat. Commun., 2015, 6, 6828.

12 (a) K. Q. Zhao, L. L. An, X. B. Zhang, W. H. Yu, P. Hu, B. Q. Wang, J. Xu, Q. D. Zeng, H. Monobe, Y. Shimizu, B. Heinrich and B. Donnio, Chem. - Eur. J., 2015, 21, 10379-10390; (b) K. Q. Zhao, X. Y. Bai, B. Xiao, Y. Gao, P. Hu, B. Q. Wang, Q. D. Zeng, C. Wang, B. Heinrich and B. Donnio, J. Mater. Chem. C, 2015, 3, 11735-11746.
13 K. Q. Zhao, Y. Gao, W. H. Yu, P. Hu, B. Q. Wang, B. Heinrich and B. Donnio, Eur. J. Org. Chem., 2016, 2802-2814.

14 (a) C. X. Liu, H. Wang, J. Q. Du, K. Q. Zhao, P. Hu, B. Q. Wang, H. Monobe, B. Heinrich and B. Donnio, J. Mater. Chem. C, 2018, 6, 4471-4478; (b) K. C. Zhao, J. Q. Du, H. F. Wang, K. Q. Zhao, P. Hu, B. Q. Wang, H. Monobe, B. Heinrich and B. Donnio, Chem. - Asian J., 2019, 14, 462-470.

15 Y. Yang, H. Wang, H. F. Wang, C. X. Liu, K. Q. Zhao, B. Q. Wang, P. Hu, H. Monobe, B. Heinrich and B. Donnio, Cryst. Growth Des., 2018, 18, 4296-4305.

16 K. Binnemans, Chem. Rev., 2005, 105, 4148-4204.

17 K. Goossens, K. Lava, C. W. Bielawski and K. Binnemans, Chem. Rev., 2016, 116, 4643-4807.

18 K. V. Axenov and S. Laschat, Materials, 2011, 4, 206-259.

19 S. Chen and S. H. Eichhorn, Isr. J. Chem., 2012, 52, 830-843.

20 S. K. Pal and S. Kumar, Biosens. Nanotechnol., 2014, 9, 267-314.

21 Q. Gao, C. Zou and W. Lu, Chem. - Asian J., 2018, 13, 3092-3105.

22 T. Kato, M. Yoshio, T. Ichikawa, B. Soberats, H. Ohno and M. Funahashi, Nat. Rev. Mater., 2017, 2, 17001.

23 T. Kato, J. Uchida, T. Ichikawa and T. Sakamoto, Angew. Chem., Int. Ed., 2018, 57, 2-19.

24 M. Yoshio, T. Mukai, H. Ohno and T. Kato, J. Am. Chem. Soc., 2004, 126, 994-995.

25 M. Yoshio, T. Ichikawa, H. Shimura, T. Kagata, A. Hamasaki, T. Mukai, H. Ohno and T. Kato, Bull. Chem. Soc. Jpn., 2007, 80, 1836-1841.

26 B. Soberats, M. Yoshio, T. Ichikawa, X. Zeng, H. Ohno, G. Ungar and T. Kato, J. Am. Chem. Soc., 2015, 137, 13212-13215.

27 A. Alam, J. Motoyanagi, Y. Yamamoto, T. Fukushima, J. Kim, K. Kato, M. Takata, A. Saeki, S. Seki, S. Tagawa and T. Aida, J. Am. Chem. Soc., 2009, 131, 17722-17723.

28 B. Dong, T. Sakurai, Y. Honsho, S. Seki and H. Maeda, J. Am. Chem. Soc., 2013, 135, 1284-1287.

29 W. Dobbs, B. Heinrich, C. Bourgogne, B. Donnio, E. Terazzi, M. E. Bonnet, F. Stock, P. Erbacher, A. L. Bolcato-Bellemin and L. Douce, J. Am. Chem. Soc., 2009, 131, 13338-13346.

30 J. J. Lee, A. Yamaguchi, M. A. Alam, Y. Yamamoto, T. Fukushima, K. Kato, M. Takata, N. Fujita and T. Aida, Angew. Chem., Int. Ed., 2012, 51, 8490-8494.

31 J. Motoyanagi, T. Fukushima and T. Aida, Chem. Commun., 2005, 101-103.

32 P. H. J. Kouwer and T. M. Swager, J. Am. Chem. Soc., 2007, 129, 14042-14052.

33 N. D. Suhan, S. J. Loeb and S. H. Eichhorn, J. Am. Chem. Soc., 2013, 135, 400-408.

34 Y. Ren, W. H. Kan, M. A. Henderson, P. G. Bomben, C. P. Berlinguette, V. Thangadurai and T. Baumgartner, J. Am. Chem. Soc., 2011, 133, 17014-17026.

35 L. Veltri, V. Maltese, F. Auriemma, C. Santillo, S. Cospito, M. La Deda, G. Chidichimo, B. Gabriele, C. De Rosa and A. Beneduci, Cryst. Growth Des., 2016, 16, 5646-5656.

36 V. Causin and G. Saielli, J. Mater. Chem., 2009, 19, 9153-9162.

37 K. Tanabe, T. Yasuda, M. Yoshio and T. Kato, Org. Lett., 2007, 9, 4271-4274. 
38 M. Krikorian, S. Liu and T. M. Swager, J. Am. Chem. Soc., 2014, 136, 2952-2955.

39 Y. Haketa and H. Maeda, Chem. Commun., 2017, 53, 2894-2909.

40 (a) D. Q. Wu, W. Pisula, V. Enkelmann, X. L. Feng and K. Mülen, J. Am. Chem. Soc., 2009, 131, 9620-9621; (b) D. Q. Wu, W. Pisula, M. C. Haberecht, X. L. Feng and K. Mülen, Org. Lett., 2009, 11, 5686-5689.

41 S. H. Kang, M. Kim, H.-K. Lee, Y.-S. Kang, W.-C. Zin and K. Kim, Chem. Commun., 1999, 93-94.

42 K. Takagi, K. Yamauchi, S. Kubota, S. Nagano, M. Hara, T. Seki, K. Murakami, Y. Ooyama, J. Ohshita, M. Kondo and H. Masu, RSC Adv., 2016, 6, 9152-9159.

43 J. Litterscheidt, P. Judge, A. Bühlmeyer, K. Bader, J. S. Bandar, T. Lambert and S. Laschat, Liq. Cryst., 2018, 45, 1250-1258.

44 S. Sauer, N. Steinke, A. Baro, S. Laschat, F. Giesselmann and W. Kantlehner, Chem. Mater., 2008, 20, 1909-1915.

45 S. K. Gupta and S. Kumar, Liq. Cryst., 2012, 39, 1443-1449.

46 L. Cui and L. Zhu, Liq. Cryst., 2006, 33, 811-818.

47 S. K. Pal and S. Kumar, Liq. Cryst., 2008, 35, 381-384.

48 S. K. Pal and S. Kumar, Tetrahedron Lett., 2006, 47, 8993-8997.

49 S. Kumar and S. K. Pal, Tetrahedron Lett., 2005, 46, 2607-2610.

50 S. Kumar and S. K. Gupta, Tetrahedron Lett., 2010, 51, 5459-5462.

51 S. Kumar and S. K. Pal, Tetrahedron Lett., 2005, 46, 4127-4130.

52 B. Miguel-Coello, M. Bardaji, S. Coco, B. Donnio, B. Heinrich and P. Espinet, Inorg. Chem., 2018, 57, 4359-4369.

53 F. Camerel, F. Kinloch, O. Jeannin, M. Robin, S. K. Nayak, E. Jacques, K. A. Brylev, N. G. Naumov and Y. Molard, Dalton Trans., 2018, 47, 10884-10896.
54 (a) M. Kaller, C. Deck, A. Meister, G. Hause, A. Baro and S. Laschat, Chem. - Eur. J., 2010, 16, 6326-6337; (b) M. Kaller, P. Staffeld, R. Haug, W. Frey, F. Giesselmann and S. Laschat, Liq. Cryst., 2011, 38, 531.

55 (a) K. Tanabe, Y. Suzui, M. Hasegawa and T. Kato, J. Am. Chem. Soc., 2012, 134, 5652-5661; (b) Y. Luo, N. Marets and T. Kato, Chem. Sci., 2018, 9, 608-616.

56 G. Park, K. Goossens, T. J. Shin and C. W. Bielawski, Chem. - Eur. J., 2018, 24, 6399-6411.

57 Y. Gao, J. M. Slattery and D. W. Bruce, New J. Chem., 2011, 35, 2910-2918.

58 M. R. Imam, M. Peterca, U. Edlund, V. S. K. Balagurusamy and V. Percec, J. Polym. Sci., Part A: Polym. Chem., 2009, 47, 4165-4193.

59 K. Q. Zhao, J. Q. Du, X. H. Long, M. Jing, B. Q. Wang, P. Hu, H. Monobe, B. Henrich and B. Donnio, Dyes Pigm., 2017, 143, 252-260.

60 K. Q. Zhao, M. Jing, L. L. An, J. Q. Du, Y. H. Wang, P. Hu, B. Q. Wang, H. Monobe, B. Heinrich and B. Donnio, J. Mater. Chem. C, 2017, 5, 669-682.

61 R. Lungwitz and S. Spange, New J. Chem., 2008, 32, 392-394.

62 D. Navarro-Rodriguez, D. Guillon, A. Skoulios, Y. Frère and P. Gramain, Makromol. Chem., 1992, 193, 3117-3128.

63 C. Destrade, M. Mondon and J. Malthête, J. Phys. Colloques, 1979, 40C3, 17-21.

64 S. J. Cross, J. W. Goodby, A. W. Hall, M. Hird, S. M. Kelly, K. J. Toyne and C. Wu, Liq. Cryst., 1998, 25, 1-11. 